\title{
Dossiê
}

REsumo
No presente artigo, discute-
se que, atualmente, na
esfera das tarefas educacio-
nais, os adultos não
pretendem introduzir as
crianças no mundo pré-
existente, mas desenvolver
suas capacidades "intrínse-
cas". De acordo com isso,
os adultos não teriam quase
mais nada a transmitir aos
mais novos. Discutem-se,
ainda, as conseqüências
politicas desse pensamento,
em especial a suposição da
"igualdade política" entre
adultos e crianças, e a
"emancipação" dos novos
em face do mundo adulto.
Descritores: psicanálise e
educação; filosofia da educa-
cão; Hanna Arendt; Freud
Hack

\section{A DISSOCIAÇÃO ENTRE A \\ NATALIDADE E O MUNDO}

\author{
Douglas Emiliano Batista
}

“'O Século da Criança', como podemos lembrar, iria emancipar a criança e liberá-la dos padrões originários de um mundo adulto.”

Hannah Arendt (1972, p. 237)<smiles>C1=CC2CCCCC(C1)C2</smiles>
uando se reflete acerca dos discursos educacionais que vingam em nossos dias, não é improvável que se perfile no horizonte a suspeita de que o nosso tempo tem produzido uma dissociação, sem precedentes na História, entre o nascimento das crianças e a reprodução simbólica do mundo.

Hoje, em particular no âmbito pedagógico, mas de modo algum restrito apenas a ele, tudo se passa como se não mais desejássemos transmitir algo àqueles que, por força tão-somente de uma contingência própria à vida, chegaram ao mundo algum tem-

Mestrando da Faculdade de Educação da USP (Fe-USP). 
po depois de nós. A transmissão, ao menos em nossos dias, é suspeita de ter se configurado no instrumento princeps da violência real com que os adultos acometeriam os mais novos, uma vez que a "atividade" dita imanente ou natural à criança - sua assim chamada "condição de sujeito" - não seria levada a sério na transmissão de conhecimentos e valores de uma geração à outra, e em especial na transmissão que se consuma na vida escolar.

Com vistas a engendrar um esboço dessa dissociação entre natalidade e mundo no âmbito educacional, pretendemos nos valer dos três famosos "pressupostos básicos" que, segundo Arendt, vieram à tona modernamente em meio à crise na educação (Arendt, 1972, p. 230).

Começaremos pelo último. O terceiro pressuposto, em vista dos demais, é o que mantém conexão mais íntima com a "teoria moderna acerca da aprendizagem" (p. 230), e que veio a ser sistematizada pelo pragmatismo. Esquematicamente, o pressuposto é de que o aprendizado só é ativo (e, portanto, legítimo) quando o aprendiz aprende fazendo, isto é, quando aprende algo fazendo-o por conta própria, fazendo-o por si mesmo. Obviamente, o que é posto em jogo com isso é o legado simbólico do adulto aos mais novos e a suposta passividade a que estes últimos estariam expostos no contexto da assim chamada escola tradicional. $\mathrm{Na}$ nova educação, ao contrário de os alunos se constituírem em depositários, ou mesmo em féretros de conhecimentos prescritos, oriundos do passado, eles produziriam - agora com as próprias mãos - o seu conhecimento. Nesse sentido, a figura do professor não mais se confundiria com a de um "transmissor", na medida em que o mestre se reservaria apenas a demonstrar "constantemente como o saber é produzido" (p. 232). No limite, trata-se de substituir o aprendizado pelo fazer.

A este terceiro pressuposto básico estaria estreitamente vinculado o segundo pressuposto apontado por Arendt, a saber: o de que a pedagogia teria se convertido numa ciência geral do ensino, ficando com isso livre das contingências próprias a cada conteúdo ou a cada disciplina a ser ministrada. Eis que, para nossa autora, foi sob a influência da psicologia moderna e do pragmatismo que se difundiu, no âmbito pedagógico, certa desídia quanto à formação geral do professorado; uma vez admitido que o velho ideal humanista de formação de professores estaria essencialmente implicado no paradigma escolar tradicional de transmissão de conhecimentos "empedernidos", "petrificados", o domínio tanto mais light de técnicas gerais de ensino seria mais útil aos professores interessados em levar o aluno a aprender de modo supostamente independente ou por si mesmo. 
Esse ponto nos leva então ao primeiro pressuposto básico a que alude Arendt: o de que existe um mundo da criança no mesmo sentido em que se pode dizer que existe um mundo comum aos adultos, um mundo publicamente compartilhado. O problema é que quando se admite a existência de uma sociedade autônoma entre as crianças, é preciso então admitir que elas mesmas a governem, ou, quando muito, que o adulto apenas as auxilie a governá-la. Isto é, tal pressuposto exige que o adulto renuncie a sua autoridade sobre as crianças para dividi-la com elas, como se as crianças já fossem responsáveis pelo mundo a que foram trazidas ou já fossem cidadãos da polis, ao contrário de estarem sendo educadas para vir a sê-lo. O apelo, portanto, é o de que os recémchegados por nascimento, emancipem-se, na medida do possível, da autoridade dos mais velhos. Todavia, Arendt demonstra que tal pretensa libertação da criança do mundo adulto ou bem termina por abandoná-la aos próprios meios ou bem subjuga-a à mais terrível das tiranias até mesmo para uma criança: a da maioria ${ }^{1}$. É que diante da maioria absoluta de um grupo de crianças que determina a uma dentre elas o que deve e o que não deve ser feito, esta última sempre se encontrará sob a esmagadora condição de ser apenas a 'minoria de um'; inexoravelmente, ela será incapaz de contra-argumentar; e irremediavelmente estará impedida de retornar ao mundo adulto (posto que foi "emancipada" sob a anuência dos mais velhos). Em verdade, o pressuposto de um mundo infantil autônomo exila as crianças do mundo dos adultos e do convívio com estes, de modo que não é surpreendente, alerta Arendt, que uma vez abandonadas a tal orfandade simbólica - mais perniciosa até mesmo que a nefasta intervenção ditatorial do adulto - as crianças se entreguem ao conformismo, à delinqüência, ou à mistura de ambos (Arendt, 1972, p. 230)2.

É bem verdade que essa "demissão do ato educacional” por parte dos adultos (tal como se a define no campo de estudos em psicanálise e educação) não lhes deve ser creditada como um ato volitivo, deliberado. Por vezes, é com a melhor das intenções senão com a mais ingênua delas - que se procura assegurar o respeito aos pretensos interesses "imanentes" da criança bem como às suas manifestações mais "genuínas" ou "inatas". A ilusão, aqui, é clássica, e foi denunciada um sem-número de vezes ao longo de boa parte da História da Filosofia do século XX (senão desde a segunda metade do XIX): trata-se da naturalização de um construto social, no caso, o da infância. E sob a influência do terceiro pressuposto (o de que aprendemos somente o que nós mesmos fazemos), o aprendizado infantil ativo - em que se "respeita" a condição de sujeito da criança - levaria em conta fundamental-

58 Estilos da Clínica, 2006, Vol. XI, n²1, 56-63 
mente o brincar - suposta manifestação inata aos pequenos ${ }^{3}-$, em detrimento do esforço, do estudo e do trabalho intelectual. Assim, o ensino dito tradicional - como que aparando os brotos imaturos nos ramos de um arbusto - cercearia a iniciativa lúdica infantil constrangendo a criança à mais absoluta passividade.

$\mathrm{Na}$ pedagogia contemporânea, esse pressuposto naturalizado oriundo da psicologia do desenvolvimento - é hegemônico, já que a educação teria por primado fazer desabrochar as potências interiores dos pequenos, ao contrário de promover paulatinamente o seu ingresso no mundo em comum partilhado por adultos. Contudo, sob a capa do respeito à "naturalidade" e à "autenticidade" das crianças, o que de fato se consuma é a exclusão dessas crianças em relação ao mundo adulto e sua retenção na suposta autonomia de um "mundo" infantil ${ }^{4}$.

Há graves repercussões da "aplicação" de teorias engendradas no campo da psicologia do desenvolvimento (onde, por sinal, elas originalmente gozam de um estatuto científico legítimo) sobre o campo pedagógico; e uma das mais graves talvez seja a de induzir professores, profissionais de educação e as próprias escolas a conceber a instituição educacional como se ela fosse essencialmente, e acima de tudo, uma instituição de cunho vocacional. Se isso é especialmente verossímil no caso do sistema americano de ensino, não o é menos em nosso próprio sistema escolar, sobretudo ao se ter em conta a larga difusão de "teorias da competência" ou de "desenvolvimento de capacidades" em nossos dias; teorias que tanto embaraçam a compreensão daquele elementar princípio público segundo o qual a escola deveria propiciar às crianças primordialmente a aquisição dos "pré-requisitos normais de um currículo padrão" (Arendt, 1972, p. 230), ou seja: assegurar a "relativa equidade na distribuição dos bens culturais" (Carvalho, 2004, p. 333 ), é condição sine qua non de os recém-chegados por nascimento virem a ser sujeitos do inestimável direito educacional de partilhar do patrimônio simbólico humano ${ }^{5}$.

$$
* * *
$$

Embora a gênese daquilo que Arendt denomina 'pathos do novo' seja anterior ao XVIII, para a autora foi somente nesse século que "O entusiasmo extraordinário pelo que é novo (...) e a concomitante confiança em uma 'perfectibilidade ilimitada'..." (1972, p. 224) assumiram sua forma propriamente conceitual e política. E tal assunção não seria, em absoluto, indiferente para o moderno ideal educacional. Segundo Arendt, esse novo ideal, em particular sob a influência de Rousseau, imprimiria à educação um teor marcadamente político, ao mesmo tempo em que imprimiria à vida política um teor propriamente educacional.

O novo ideal - em comum nesse ponto com as antigas utopias políticas - assentou-se sobre o pressuposto de que uma nova ordem do mundo deveria principiar pela educação dos mais novos. Por sinal, não foi com outro objetivo que as modernas tiranias procuraram doutrinar as crianças em as afastando de seus 
pais. Tratava-se, mesmo nesses casos, da pretensão de educar os novos para "o futuro", como se o futuro já estivesse de fato consumado.

Para a nossa autora, entretanto, "a educação não pode desempenhar papel nenhum na política" (1972, p. $225)$, posto que, ao educar adultos, o mundo público é equiparado ao mundo privado sob a forma paradigmática da relação hierárquica entre pai e filho; e, inversamente, quando se supõe a existência de um "mundo" infantil, tal hierarquia pré-política - imprescindível na esfera privada do lar - é equiparada à igualdade política do mundo público. Em suma: no primeiro caso, atribui-se minoridade aos adultos; no segundo, maioridade às crianças.

Para Arendt, foi a introdução da esfera social - instância em que a vida aparece como o bem supremo da humanidade - entre o domínio privado do lar e o mundo comum que engendrou a elisão crescente da fronteira entre esses dois âmbitos. As atribuições da escola, sob tal elisão, restaram obnubiladas, uma vez que é a educação escolar que inicia a criança na transição do âmbito privado à vida em comum. Não é fortuito, portanto, que muitas escolas ostentem hoje a imagem de "segundo lar" de seus alunos. Em termos psicanalíticos, poder-se-ia dizer que tal rebaixamento da atribuição da escola termina por imprimir novas dificuldades aos pequenos no tocante à dissolução do complexo de Édipo, isto é, no tocante à saída do drama privado familiar.

É interessante notar que também para Max Weber "a política não tem

60 Estilos da Clínica, 2006, Vol. XI, n² 21, 56-63 
seu lugar nas salas de aulas das universidades" (2004/1918, p. 38), tanto no que concerne aos discentes quanto - e em especial - no que concerne aos docentes. Configura para o autor, pois, improbidade intelectual por parte dos professores negligenciarem a distinção entre, por um lado, a análise científica da política e, por outro, o apelo com vistas a uma tomada de posição. É imperdoável que o mestre, em sala de aula, se valha da assimetria de sua palavra para impor a seus discípulos esta ou aquela convicção política; ao contrário, deveria fazê-lo em lugar público e onde possa vir a ser criticado, estando ante o "contato pessoal de homem para homem" (Weber, 2004/1918, p. 44) e sob iguais condições, em vista dos que aparecem então como seus adversários na polis.

A afinidade entre o pensamento de Weber e Arendt, ao menos neste ponto em particular, não é de modo algum negligenciável: educar e persuadir são, para ambos, ações heterogêneas ${ }^{6}$. A persuasão exige a igualdade política, que somente pode ocorrer entre adultos. Já a educação pressupõe uma diferença e uma hierarquia entre a cátedra e o banco escolar, de modo que é ilegítima a persuasão dos mais novos.

E é exatamente por que os novos não compõem um "corpo político" que não se deve então reivindicar sua emancipação do mundo adulto, nem tampouco educá-los para que - como "minoria oprimida" - deponham do poder a suposta "maioria adulta" Talvez Freud, afinal, também tivesse isso em mente quando - ao abordar questões educacionais - afirmou: "penso até mesmo que as crianças revolucionárias não são desejáveis, sob nenhum ponto de vista" (Freud, 1933/1976, p. 185). Como assevera Arendt, é exatamente "em benefício daquilo que é novo e revolucionário em cada criança que a educação precisa ser conservadora" (1972, p. 243), uma vez que a "preparação" dos recém-chegados para a existência em um 'mundo futuro' subtrai-lhes a oportunidade de engendrarem eles mesmos - a partir do mundo dos velhos - algo historicamente original e distinto de um futuro aviltado, prenunciado (posto não ser mais do que a reedição de um futuro sonhado pelas gerações passadas). As ações que têm em vista implementar uma nova ordem do mundo, ou seja, que se empenham em imprimir mudanças ao status quo, são admissíveis somente na política, onde os adultos se encontram junto a seus pares no mundo.

Em razão de ter sido criado pelos próprios mortais que o habitam, o mundo comum tem de continuamente ser "posto nos eixos" (Arendt, 1972, p. 243). Podemos dizer, então, que o impossivel da educação - referido por Freud - remonta a não se poder assegurar a priori que o mundo seja de novo colocado "em seus eixos". Contudo, a esperança de renovação do mundo humano subsiste, se 
a educação - à medida que faz jus ao passado - não coloniza o futuro, impossibilitando que os novos demarquem sua diferença em vista do mundo velho (embora o façam a partir deste). É, pois, somente sob tal premissa que se pode asseverar, ao nascer de uma criança, que o mundo humano torna a começar.

\begin{abstract}
DISSOCLATION BETWEEN NATALITY AND THE WORLD

In this paper, we discuss that, nowadays, in the sphere of educational tasks, adults ones do not intend to introduce children into an already existing world, but to develop their 'intrinsic' capacities. According to this, adults would have almost nothing to transmit to the new ones. We also discuss the political consequences of that thought, specially the supposition of the 'political equality' between adults and children, and the 'emancipation' of new ones from the adult world. Index terms: psychoanalysis and education; philosophy of education; Hanna Arendt; Freud
\end{abstract}

\title{
RESUMEN
}

LA DISOCLACIÓN ENTRE LA NATALIDAD Y LO MUNDO

En este texto discútese que en el campo educativo, los adultos no pretenden en la actualidad introducir los niños en el mundo pre-existente, sino mas bien desarrollar sus capacidades intrínsecas. Piensase que los adultos no tienen nada a transmitir. Mas aún, discútense las consecuencias políticas de ese tipo de pensamiento, como, em particular, la suposición de la igualdad politica entre adultos y niños y la emancipación de estos frente al mundo adulto. Palabras clave: psicoanálisis y educación; filosofia de la educación; Hanna Arendt; Freud

\section{REFERÊNCIAS BIBLIOGRÁFICAS}

Arendt, H. (1972). A crise na educação. In H. Arendt, Entre o passado e o futuro (pp. 221-247). São Paulo: Perspectiva.

Carvalho, J. S. F. (2004). "Democratização do ensino" revisitado. Revista Educação e Pesquisa, 30 (2), 327-334.

Freud, S. (1976). Conferência XXXIV: Explicações, aplicações e orientações. In S. Freud, Edição standard brasileira das obras completas de Sigmund Freud (J. Salomão, trad., Vol. 22, pp. 167-191). Rio de Janeiro: Imago. (Trabalho original publicado em 1933)

Lajonquière, L. de (1999). Infância e ilusão (psico)pedagógica: Escritos de psicanálise e educaşão. Petrópolis, RJ: Vozes.

Rosa, G. (1986). Grande sertão: Veredas. Rio de Janeiro: Nova Fronteira.

Weber, M. (2004). Ciência e política: Duas vocaçoes (L. Hegenberg \& O. S. Mota, trad.). São Paulo: Cultrix. (Trabalho original publicado em 1918)

62 Estilos da Clínica, 2006, Vol. XI, n²1, 56-63 


\section{Dossiê}

NOTAS

1 "A autoridade de um grupo, mesmo que este seja um grupo de crianças, é sempre consideravelmente mais forte e tirânica do que a mais severa autoridade de um indivíduo isolado" (Arendt, 1972, p. 229).

2 Resguardadas as proporções e a temática social, talvez o filme Cidade de Deus, dirigido por Fernando Meirelles, não fale de outra coisa.

3 Para a psicanálise, o que se passa na cena inconsciente da criança ao brincar é a tentativa - em nada natural - de se enlaçar à genealogia humana, à história parental, haja vista que não se brinca de ser criança, mas de ser adulto, e de fazer o que fazem os adultos.

${ }^{4}$ No dizer de Arendt, mesmo as crianças mais velhas, sob tal pressuposto (psico)pedagógico, são mantidas "o mais possível ao nível da primeira infância” (1972, p. 232).

5 É importante não perder de vista que a universalização do acesso ao patrimônio cultural não prescinde do cultivo de práticas escolares democráticas; não prescinde nem mesmo da "convivência com professores e demais profissionais da educação que promovam essa forma de vida e, no curso de suas aulas, no conteúdo de seus ensinamentos, nas suas práticas pedagógicas" (Carvalho, 2004, p. 333); difundam e promovam os valores da democracia para além da hoje predominante - retórica moralista, ou da mera dissimulação de procedimentos democráticos.

${ }^{6}$ Contudo, não se deve desconsiderar que as razões esgrimidas por Weber, diferentemente das de Arendt, dizem respeito à impossibilidade de conciliação entre as diversas ordens de valores na modernidade (politeísmo laicizado) e a conseqüente improbidade intelectual em que incorre o professor ao in- culcar convicções em seus alunos; principalmente quando o melhor serviço que lhes pode prestar é o de esclarecer tanto os pressupostos quanto as conseqüências implicados direta e indiretamente na adesão ao culto deste ou daquele deus.

${ }^{7}$ E tal como se o adulto, por definição, fosse uma espécie de "desvio politicamente incorreto".

8 Até porque no campo educacional, ao menos aos olhos da psicanálise, o ponto de chegada nunca corrobora o ponto de saída (razão da impossibilidade própria a tal campo). Daí que talvez nada seja mais reificante e ditatorial do que pretender pautar a pedagogia pelo paradigma "estímulo-resposta", ou seja, do que pretender controlar tecnicamente a "aprendizagem" ou os efeitos da palavra do professor em vista do aluno. demilian@uol.com.br

Recebido em outubro/2006. Aceito em novembro/ 2006. 